\title{
Ascending-descending aortic bypass with valve-sparing root replacement for coarctation with aortic root aneurysm
}

\author{
Nicholas D. Andersen, MD, ${ }^{a}$ Judson B. Williams, MD, ${ }^{a}$ J. Kevin Harrison, MD, ${ }^{b}$ and G. Chad Hughes, MD, ${ }^{a}$ \\ Durham, NC
}

\begin{abstract}
A 55-year-old man with critical aortic coarctation, aortic root aneurysm, and aortic insufficiency underwent median sternotomy for ascending-descending aortic bypass and aortic root replacement. The patient was found to have a salvageable trileaflet aortic valve, allowing for valve-sparing root replacement (VSRR). Aortic bypass with VSRR has not previously been reported and may be the ideal operation for repair of coarctation with concomitant aortic root aneurysm.
\end{abstract}

\section{CLINICAL SUMMARY}

The patient is a 55-year-old man with lifelong lower extremity claudication and severe hypertension requiring 4 antihypertensive agents. He had been followed up yearly by transthoracic echocardiography for aortic root dilation, aortic insufficiency, and suspicion of bicuspid aortic valve. He was referred for surgical consultation after a computed tomographic angiogram revealed critical aortic coarctation with progressive root dilation.

On examination, the patient was found to have an armleg systolic pressure differential of $35 \mathrm{~mm} \mathrm{Hg}$ with brachiofemoral pulse delay. Femoral pulses were faint and pedal pulses were absent. Review of the computed tomographic angiogram revealed critical coarctation of the aorta distal to the left subclavian artery with a luminal diameter of less than $1 \mathrm{~mm}$ and extensive collateral thoracic vasculature. The arch was hypoplastic and the left subclavian artery was dilated to $21 \mathrm{~mm}$. The aortic root measured $5.0 \mathrm{~cm}$ on 3-dimensional cross-sectional imaging. Transthoracic echocardiography demonstrated $2+$ moderate aortic insufficiency, although the aortic valve was

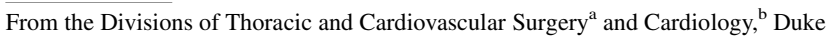
University Medical Center, Durham, NC.

Funding provided by Thoracic Surgery Foundation for Research and Education Research Fellowship (to N.D.A.) and National Institutes of Health grants T32-HL069749 and U01-HL088953 (to J.B.W.).

Disclosures: Authors have nothing to disclose with regard to commercial support.

Received for publication July 14, 2011; accepted for publication July 22, 2011; available ahead of print Aug 24, 2011

Address for reprints: G. Chad Hughes, MD, Director, Aortic Surgery Program, Duke University Medical Center, Division of Thoracic and Cardiovascular Surgery, Box 3051, Durham, NC 27710 (E-mail: gchad.hughes@ duke.edu)

J Thorac Cardiovasc Surg 2012;143:514-5

$0022-5223 / \$ 36.00$

Copyright (c) 2012 by The American Association for Thoracic Surgery

doi:10.1016/j.jtcvs.2011.07.047 not well visualized. Left ventricular systolic function was preserved.

The decision was made to proceed with median sternotomy for ascending-descending aortic bypass and aortic root replacement to address the combination of pathologic conditions in a single operation. Cardiopulmonary bypass $(\mathrm{CPB})$ was instituted via the right axillary artery and dual-stage right atrial venous cannulation. Intraoperative transesophageal echocardiography as well as direct inspection of the aortic root revealed a trileaflet aortic valve of good quality with no stress fenestrations, allowing for a reimplantation VSRR with a 30 -mm Vascutek Valsalva graft (Vascutek Ltd, Inchinnn, Scotland, United Kingdom). Before the root portion of the procedure was performed, an $18-\mathrm{mm} \times 40$-cm woven Dacron graft was anastomosed to the descending thoracic aorta via a posterior pericardial approach. After completion of the VSRR, the descending graft was tunneled around the right heart border over the inferior vena cava and anastomosed to the neo-ascending aortic graft. ${ }^{1}$ The patient was weaned from CPB uneventfully. Total aortic crossclamp time was 185 minutes and CPB time was 283 minutes. Completion transesophageal echocardiography revealed no aortic insufficiency, and monitoring of radial and femoral arterial line pressures demonstrated no residual upper extremity-lower extremity pressure gradient, down from more than $40 \mathrm{~mm} \mathrm{Hg}$ at the start of the procedure.

The patient was discharged on postoperative day 6 after an uneventful recovery. Cardiac magnetic resonance imaging performed 6 months later demonstrated a perfectly competent trileaflet aortic valve with no insufficiency, as well as a widely patent aortic bypass graft (Figure 1). The patient's lower extremity claudication symptoms had resolved and he had been weaned to 2 antihypertensive agents.

\section{DISCUSSION}

Coarctation of the aorta is associated with premature death owing to an increased rate of cardiovascular and cerebrovascular events. Repair can be achieved by transcatheter dilation and stenting or anatomic surgical correction via left thoracotomy. When concomitant cardiac disease is present, median sternotomy with extra-anatomic aortic bypass allows for coarctation repair simultaneously with additional 


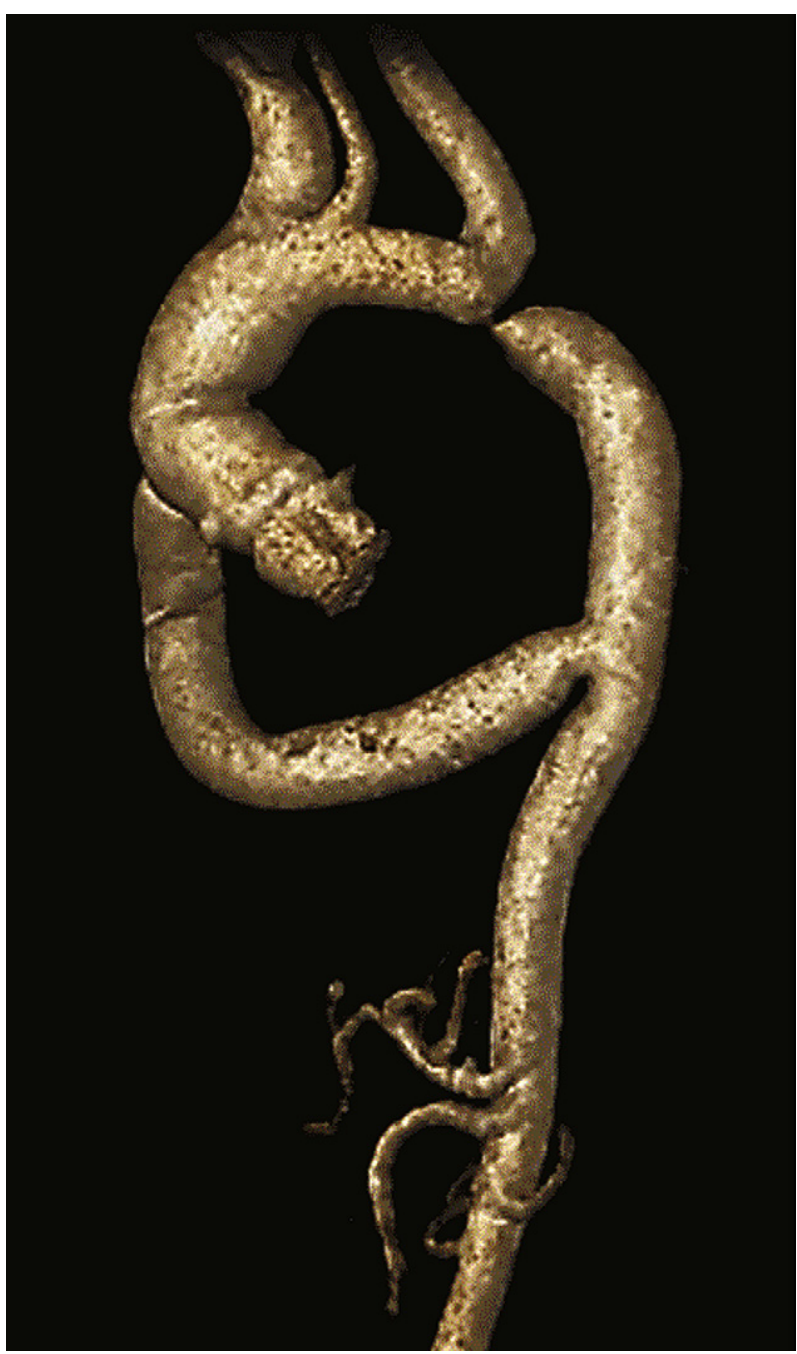

FIGURE 1. Three-dimensional magnetic resonance imaging reconstruction demonstrating critical aortic coarctation with a patent aortic bypass 6 months after combined valve-sparing aortic root replacement and ascending-descending bypass operation.

cardiac procedures. In addition, extra-anatomic aortic bypass reduces complications associated with extensive mobilization of the aorta during thoracotomy, such as hemorrhage from enlarged collateral blood vessels, recurrent laryngeal or phrenic nerve injury, and spinal cord ischemia. $^{2}$

Coarctation repair was indicated in our patient owing to the presence of severe hypertension, an arm-leg systolic pressure differential greater than $30 \mathrm{~mm} \mathrm{Hg}$, and symptoms of lower extremity claudication. The lesion was not considered amenable to transcatheter intervention in the primary setting given the severity of constriction. Further, the presence of aortic root dilation and aortic insufficiency meeting thresholds for repair $^{3}$ prompted the correction of all pathologic conditions during a single operation.

At operation, the patient was found to have a trileaflet aortic valve suitable for VSRR. In the most recent series of aortic bypass for coarctation, $7(16 \%)$ of 43 patients underwent prosthetic aortic valve and root replacement (Bentall procedure) for aortic insufficiency with root or ascending aneurysm, and the mean age of these patients was 39 years. $^{2}$ The current report demonstrates the feasibility of performing VSRR concomitant with extra-anatomic aortic bypass with excellent results. Given the young age of patients being referred with adult coarctation, ${ }^{1,2}$ when feasible, aortic bypass with VSRR may be the preferred operation to treat the not uncommon combination of coarctation with aortic root aneurysm and thereby reduce the risks of anticoagulation and reoperation associated with prosthetic valves.

\section{References}

1. McKellar SH, Schaff HV, Dearani JA, Daly RC, Mullany CJ, Orszulak TA, et al. Intermediate-term results of ascending-descending posterior pericardial bypass of complex aortic coarctation. J Thorac Cardiovasc Surg. 2007;133: 1504-9.

2. Wang R, Sun LZ, Hu XP, Ma WG, Chang Q, Zhu JM, et al. Treatment of complex coarctation and coarctation with cardiac lesions using extra-anatomic aortic bypass. J Vasc Surg. 2010;51:1203-8

3. Cozijnsen L, Braam RL, Waalewijn RA, Schepens MA, Loeys BL, van Oosterhout MF, et al. What is new in dilatation of the ascending aorta? Review of current literature and practical advice for the cardiologist. Circulation. 2011; 123:924-8. 